\title{
DIVERSIDADE ECOLÓGICA, CULTURAL E LINGUÍSTICA REFLETIDA NO LÉXICO DE COMUNIDADES TRADICIONAIS
}

\author{
(Ecological, cultural and linguistic diversity present in \\ traditional communities)
}

Gilberto Paulino de Araújo ${ }^{1}$

(Universidade de Brasília- UnB)

\begin{abstract}
This study analyzes the linguistic process (focus on the lexicon) that takes place in the interrelationship between traditional communities and their environment, taking into consideration among others biodiversity, cultural and linguistic diversity. Through literature review (research in traditional communities present in several locations worldwide), the research shows that these interactions not only exist; they are inextricable, as Maffi put it.

Keywords: Diversity, environment, traditional knowledge, minority languages.

\section{RESUMO}

O presente estudo faz uma análise do processo linguístico (foco no léxico) que ocorre no inter-relacionamento das comunidades tradicionais com o seu meio ambiente, tendo como base a relação entre biodiversidade, diversidade cultural e diversidade linguística. Por meio da revisão bibliográfica (pesquisas realizadas em comunidades tradicionais presentes em diversas localidades do mundo), o trabalho mostra como se dá esse processo de interdependência entre os fatores linguísticos, culturais e ecológicos, de modo inextricável como afirma Maffi.

Palavras-chave: Diversidade, meio ambiente, conhecimento tradicional, línguas minoritárias.
\end{abstract}

1. Doutorando em Linguística na UnB, com trabalho de pesquisa voltado para a etnoecologia linguística dos Kalungas do norte de Goiás. 


\section{Introdução}

À luz dos estudos ecolinguísticos, cuja fundamentação teórica propõe o estudo das relações entre língua e meio ambiente, o presente estudo tem por objetivo analisar o processo linguístico (foco no léxico) que ocorre no inter-relacionamento de comunidades tradicionais com o seu meio ambiente, tendo como base a interdependência entre diversidade ecológica, diversidade cultural e diversidade linguística.

Primeiramente, o estudo faz uma breve explanação de como língua, cultura e meio ambiente estão inter-relacionados. Em seguida, com base na revisão bibliográfica (Smith, 2001; Mühlhäusler, 2001; Rodrigues, 2001; Couto 2007), mostra algumas evidencias da presença de um maior número de línguas em regiões do mundo onde há, também, uma grande diversidade de espécies de plantas e animais; e como os danos ocasionados aos ecossistemas vêm acompanhado de perdas culturais e linguísticas. Por último, aborda os efeitos dessa interrelação no léxico dessas comunidades, tendo como base a presença de termos empregados pelos membros das comunidades tradicionais para descrever o meio ambiente local.

\section{Diversidade biológica, cultural e linguística}

A interação do ser humano com a natureza representa muito mais que a simples sobrevivência da espécie, sempre fomos (e continuaremos a ser) dependentes dela para suprir desde as nossas necessidades mais básicas, como alimentação e moradia, até as nossas mais complexas que compreendem o bem-estar físico, mental e espiritual. Esse processo de interação ao longo da história da humanidade imprimiu formas diferentes de conhecer e tratar o meio ambiente circundante e, até mesmo, os espaços mais longíquos nos quais os diferentes povos ou civilizações se aventuraram a 'dominar' e/ou se estabelecer. Tal fato nos revela que, para uns tantos, a natureza é vista apenas como uma fonte 'inesgotável' de recursos para a permanente e demasiada exploração e, consequentemente, o acúmulo de riquezas e poder. 
Ainda assim, inúmeras sociedades humanas desenvolveram formas mais harmoniosas de interagir com a natureza, pautadas pelo cuidado e respeito ao meio ambiente do qual fazem parte. Práticas de convivência que resultaram no surgimento de valores, conhecimentos culturais expressos e compartilhados por meio de um grande número de línguas existentes (e muitas outras já extintas) no mundo, sendo estas a maioria faladas por pequenas comunidades indígenas e tradicionais. Explica Rodrigues (2001):

Assim como a diversidade biológica é produto de milhares de anos de evolução, isto é, da interação entre as espécies, de migrações para novos meios ambientes, de adaptação a mudanças climáticas, etc., também a diversidade cultural e linguística ou, numa palavra, a diversidade etnolinguística decorre de processos seculares e milenares de dispersão de grupos humanos e de interação de uns com outros e com novos meios ambientes (Rodrigues, 2001, p. $269)^{2}$.

Desse modo, podemos enxergar as pistas que nos revelam de que forma língua, cultura e meio ambiente estão inter-relacionados, uma vez que em cada espaço do planeta (com condições de vida humana) é possível identificar grupos de pessoas que possuem práticas sociais e econômicas, ou melhor, formas de administrar os seus ecossistemas que, de alguma forma, estão incorporadas às suas culturas e suas línguas. Nas palavras de Maffi (2005, p. 602), "diversidade biocultural: diversidade de vida em todas as suas manifestações - biológica, cultural e linguística - que estão inter-relacionadas em um sistema adaptativo sócio-ecológico" ${ }^{3}$.

2. É possível a divergência na apresentação do número da página desta referência em relação à versão original impressa, uma vez que esta versão encontra-se em formato de arquivo eletrônico pdf disponível em: <http://www.amazoe.org.br/ textoreferencia/biodiversidade_e_diversidade_etnolinguistica.pdf $>$. Acesso em 05/08/2012)

3. "Diversidade biocultural: diversidade de vida em todas as suas manifestações - biológica, cultural e linguística - que estão inter-relacionados dentro de um complexo sistema sócio-ecológico adaptativo" (tradução minha). 
Segundo pesquisadores dedicados à ecolinguística e etnociências ${ }^{4}$, a interdependência entre língua, conhecimento e meio ambiente se traduz nas fortes correlações, em nível global, entre a diversidade total das culturas humanas e línguas (isto é, a diversidade cultural e linguística) e a diversidade total da natureza (isto é, a biodiversidade).

Para tais estudiosos, esta inter-relação ainda é especialmente evidente nas sociedades tradicionais (ou povos locais), tendo em vista que estas comunidades mantêm uma maior proximidade entre os laços materiais e espirituais com o meio ambiente. Dessa maneira, o conhecimento ecológico tradicional é resultante e resulta em práticas acumuladas ao longo de gerações as quais possibilitam a estes povos satisfazerem suas necessidades sem que coloquem em risco a preservação do meio ambiente e o bem-estar de seus pares.

De acordo Maffi (2001), a habilidade de nos relacionarmos com o meio ambiente resulta do próprio conhecimento sobre ele combinado ao conhecimento específico da própria língua. Assim, aprendendo as fontes de conhecimento local, como dos habitantes de comunidades tradicionais, povos das florestas tropicais, nômades do deserto, isso pode resultar numa base maior de informações sobre a sobrevivência sustentável de nossa espécie, uma vez que este conhecimento está intimamente ligado à língua. ${ }^{5}$

Para Mühlhäusler (2010), a diversidade das línguas e a diversidade biológica são interdependentes. Nessa perspectiva, os

4. Os estudos sobre a interdependência entre a diversidade ecológica, cultural e a diversidade linguística possuem um caráter especificamente interdisciplinar, integrando as contribuições de linguistas, antropólogos, psicólogos, biólogos, cientistas sociais, entre outros, como é o caso da obra On biocultural diversity: linking language, knowledge, and the environment, organizada por Maffi (2001). Outras informações também podem ser acessadas na página eletrônica da ONG Terralíngua: <www.terralingua.org $>$.

5. A ONG Terra Língua ressalta a necessidade de defesa da diversidade linguística, cultural e biológica, destacando que (a) a diversidade de línguas e suas variantes é uma componente vital da diversidade cultural do planeta; (b) a diversidade cultural e a diversidade biológica não só estão intimamente conectadas como são frequentemente inseparáveis; e (c) tal como as espécies biológicas, muitas línguas e suas variantes enfrentam, a nível mundial, uma crise de uma magnitude sem precedentes, em que a sua própria sobrevivência está em jogo. 
saberes tradicionais revelam que a linguagem está significativamente envolvida com as percepções humanas do ambiente físico e social. Essa percepção é culturalmente construída e está intrinsecamente relacionada com a linguagem, visto que por meio desta são externadas as ações, ideologias e, até mesmo, a própria ciência.

$\mathrm{O}$ autor apresenta três argumentos a favor da necessidade de uma visão ecolinguística da língua (e, nesse caso, podemos também dizer etnoecológica):

a) argumento moral: o direito de cada ser humano falar a sua língua como um marcador de sua identidade, de ser educado nela e de mantê-la se assim o desejar;

b) argumento científico: línguas diferentes contêm diferentes saberes e conhecimentos de diversas pessoas; isso pode ser um precioso recurso no processo de soluções para os problemas das sociedades atuais.

c) argumento econômico: a diversidade linguística pode ser capaz de desenhar uma multiplicidade de experiências (por exemplo, na área de gestão ambiental, as diferentes práticas agrícolas, a resolução de conflitos e assim por diante), as quais promoveriam novas possibilidades de gestão a um custo mais baixo.

Em consonância, Couto (2007, p. 46) afirmar que "a ecolinguística nos convida a encarar os fenômenos da linguagem do ponto de vista do respeito e da preservação da vida, em todas as suas manifestações". Para o autor, a base dos estudos ecolinguísticos encontra-se nas inter-relações estabelecidas pelos membros de uma comunidade, na convivência destes indivíduos ao longo do tempo, e no ambiente do qual fazem parte. É nesse contexto que ocorre a interação comunicativa, onde os pares vivem seus conflitos e/ou comungam harmonicamente dos mesmos interesses.

Desse modo, a diversidade biológica, cultural e linguística integra um complexo ecossistema que vem sofrendo as consequências das ações de cunho político-econômico impressas pelo atual modelo de desenvolvimento, ainda baseado no uso indiscriminado dos recursos naturais e na exploração de grupos humanos, e que desse modo, tem colocado em risco a preservação 
da biodiversidade, de culturas e línguas dos povos minoritários e/ ou tradicionais. ${ }^{6}$

Assim, veremos adiante alguns estudos que demonstram como a diversidade biológica, a diversidade cultural e a diversidade linguística estão intrinsecamente inter-relacionadas, levando em consideração a investigação de estudiosos que, por meio de pesquisas de campo em diferentes regiões do mundo, observaram a presença de um maior número de línguas em regiões onde há uma grande diversidade de espécies de plantas e animais. ${ }^{7}$ Além disso, veremos os efeitos dessa inter-relação no léxico dessas comunidades, tendo como base a presença de um rico vocabulário para descrever a cultura e o meio ambiente local.

\section{Algumas evidências}

O estudo realizado por Smith (2001), resultante da investigação feita em diversas regiões do norte da América (Ártico, Califórnia, Planície, Platôs, entre outros) evidenciou a inter-relação entre diversidade ecológica, cultural e linguística. Para reforçar a sua análise, o pesquisador utilizou alguns números e estatísticas de outros continentes (África Central, Sudeste Asiático, Papua Nova Guiné e Melanésia).

6. Segundo os especialistas da ONG Terra Língua, embora os povos indígenas e comunidades locais sejam afetados mais diretamente pela perda de diversidade biocultural, ninguém está imune. O esforço para restaurar e manter a diversidade da vida na natureza e na cultura é uma causa que todos nós devemos compartilhar, não importa quem somos, onde e como vivemos. A vida não é dispensável.

7. De acordo com António Teixeira, colaborador da ONG Terra Língua, a diversidade ecológica e a diversidade linguística estão intrinsecamente ligadas. Ele afirma isso com base no estudo de quatro pesquisadores estadunidenses (disponível no site da revista Mother Jones): 70\% dos idiomas do mundo são encontrados nas regiões biologicamente mais ricas, e que assim como as espécies de plantas e animais ameaçadas, muitos deles também correm risco de extinção. Eles examinaram 35 regiões com um número excepcionalmente alto de espécies endêmicas, que perderam pelo menos $70 \%$ do seu habitat. Estas áreas correspondem a apenas $2,3 \%$ da superfície terrestre, mas contém mais da metade das plantas vasculares e 43\% dos vertebrados terrestres existentes no planeta. Elas também são o berço de 3202 idiomas - quase metade das línguas faladas no mundo todo. 
A pesquisa foi norteada por três hipóteses:

a) $\mathbf{1}^{\text {a }}$ hipótese -comunidades pequenas (tradicionais) preservam e valorizam a biodiversidade, resultando no maior conhecimento linguístico-cultural do meio ambiente;

b) $2^{\text {a }}$ hipótese $-\mathrm{A}$ biodiversidade do local facilita o surgimento da diversidade linguístico-cultural;

c) $3^{\text {a }}$ hipótese - grandes comunidades (large-scale) perdem diversidade linguística, cultural e biológica.

$\mathrm{O}$ autor verificou a presença de um grande número de línguas existentes, assim como uma rica diversidade cultural e biológica nessas regiões. Por meio do levantamento e comprovação das hipóteses (que não são mutuamente exclusivas), constatou que comunidades pequenas/tradicionais preservam e valorizam a biodiversidade, resultando no maior conhecimento linguístico-cultural do meio ambiente. Observou, ainda, que a biodiversidade do local facilita o surgimento da diversidade linguístico-cultural, aliada a alguns fatores ecológicos e sociopolíticos envolvidos nesse processo, como a maior permanência no local em virtude das condições satisfatórias para determinado grupo humano e a forma como os recursos naturais são utilizados pela comunidade, isto é, o equilíbrio do ecossistema é resultante da inter-relação entre população/ cultura/ língua/ meio ambiente.

Um outro estudo, realizado por Mühlhäusler (2001), tendo como base o conhecimento tradicional dos povos aborígenes australianos (conforme estimativas, estes vivem na Austrália há 50 ou 60 mil anos), evidenciou um grande domínio dessas comunidades sobre a biodiversidade local. Para subsidiar sua análise, o linguista descreve os exemplos das ilhas de Pitcairn e Norfolk.

No caso de Pitcairn, a ilha foi habitada por ingleses e taitianos sobreviventes de um naufrágio no século XVIII. A adaptação destes ao novo território evidenciou, num primeiro momento, o não conhecimento da biodiversidade do local. Com o passar do tempo, houve o desenvolvimento da língua crioula (inglês com léxico taitiano) e os moradores passaram a ter um maior conhecimento da biodiversidade local, sendo comprovada a ampliação e a presença de um léxico para o registro e partilha desse conhecimento. 
Já Norfolk foi habitada inicialmente por navegadores ingleses. Em seguida, tornou-se colônia penal da coroa britânica e posteriormente local de "missão" religiosa (educação dos mestiços aborígenes/ ingleses). Como não houve fixação de um grupo neste território, não houve o desenvolvimento do conhecimento da biodiversidade por nenhum desses grupos que aí se estabeleceram.

Diante disso, Mühlhäusler (2001) destaca dois aspectos relativos à inter-relação entre língua, cultura e meio ambiente:

a) nomeação: o conhecimento da biodiversidade é realizado quando ocorre a nomeação (lexema(s) específico (s) para as espécies). Assim, o conhecimento biológico só se torna um conhecimento genuíno quando passa a fazer parte da língua.

b) território: a comunidade só domina o conhecimento da biodiversidade a partir do momento que se fixa por várias gerações neste território.

Destarte, observamos a presença de fatores ecológicos, sociais, políticos e econômicos envolvidos nesse processo: (a) determinado grupo humano migra e se fixa num território 'apto' para a sua permanência; (b) a permanência no local ocasiona um maior contato com o ambiente local, gerando maior conhecimento ecológico (consequentemente, cultural e linguístico); (c) o domínio/manutenção do conhecimento (tradicional) com o meio ambiente possibilita a satisfação das necessidades da população (de acordo com a cultura da comunidade, esta poderá ou não comprometer o equilíbrio ecológico com base no uso dos recursos do território).

Podemos citar ainda o estudo de Rodrigues (2001) a respeito da diversidade etnolinguística na Amazônia brasileira. Neste, o autor ressalta que "a cada língua corresponde, na realidade, um complexo etnolinguístico, um corpo de hábitos, experiências, conhecimentos, maneiras de ver e de sentir para os quais essa língua tem expressão adequada e imediatamente disponível” (Rodrigues, 2001, p. 269).

O linguista destaca ainda que a importância da diversidade etnolinguística da Amazônia não se deve somente ao grande número de línguas e etnias, mas principalmente pelas singularidades de cada uma delas. Explica que a disposição geográfica da Amazônia fez com 
que esta região permanecesse isolada de outras regiões do mundo desde seu povoamento há 12.000 anos até a chegada dos europeus, há cinco séculos, ocasionando o surgimento de especificidades linguísticas (fenômenos fonéticos, fonológicos e gramaticais) e, consequentemente, culturais locais.

No que tange mais particularmente às línguas, a previsível ocorrência de fenômenos novos ou raros vem-se confirmando paulatinamente, na medida em que se estende e se intensifica a investigação científica das línguas amazônicas. Nos vários planos estruturais dos sistemas linguísticos e também nas situações de uso social das línguas encontram-se fenômenos antes desconhecidos, alguns dos quais têm levado à revisão de generalizações teóricas feitas sem seu conhecimento (RODRIGUES, 2001, p. 271).

Ainda com base no autor, ressaltamos que a exploração da região, iniciada durante a colonização europeia, causou a extinção da maioria das etnias e das línguas indígenas amazônicas. Das cerca de 700 línguas e etnias estimadas no momento da chegada dos colonizadores, contamos hoje com apenas 20\%, ou seja, não mais que 140 línguas. Além disso, deste pequeno número que restou, a maioria encontra-se ameaçada ou corre risco de desaparecer devido à situação precária em que vivem as comunidades, sendo levadas a abandonar seu tradicional estilo de vida como consequência do avanço da fronteira urbana.

Em alguns casos a língua está moribunda porque seus falantes jovens, diante de pressões e apelos externos, estão usando preferencialmente ou exclusivamente outra língua, agora em geral o Português; em outros casos, é o próprio povo que está no fim, reduzido a uma ou duas famílias, quando não a um ou dois indivíduos - com a morte destes a língua terá cessado de existir (Rodrigues, 2001, p. 273).

Dessa maneira, a perda da biodiversidade representa também o desaparecimento de línguas, culturas e conhecimentos tradicionais, evidenciando a estreita relação entre os fatores ecológicos, a pluralidade linguística e cultural. Toda essa diversidade deve ser vista sob uma nova perspectiva que considere que a manutenção dos ecossistemas 
naturais implica sustentabilidade ambiental, econômica, social, além da sobrevivência das línguas e culturas, independentemente do número de falantes ou do peso político que tenham. ${ }^{8}$

\section{Reflexos no léxico}

Nesta seção, veremos como o léxico empregado para designar o nome das plantas, dos animais e do próprio lugar ou territórios em que se encontram as comunidades tradicionais representa o saber partilhado que existe na consciência desses falantes, ou seja, dá indícios da inter-relação entre a diversidade ecológica, a diversidade cultural e linguística.

Tais estudos pertencem ao campo da etnoecologia linguística, ramo da ecolinguística (em interface com as etnociências) que investiga como pequenas comunidades se inter-relacionam com plantas, animais e com o próprio lugar ou territórios em que se encontram por meio da linguagem.

Seguem as subáreas que compõem a etnoecologia linguística:

a) Etnoantroponímia: é o "estudo dos nomes que membros de comunidades indígenas, rurais e/ou tradicionais se dão internamente". Por meio do estudo dos nomes próprios em pequenas comunidades, é possível perceber como ocorrem as relações destes consigo mesmos (Couto, 2007, p. 260).

b) Etnotoponímia: é o estudo dos nomes de lugares (topônimos) de pequenas comunidades tradicionais em geral,

8. Nesse sentido, a ONG Terra Língua declara que (a) cada língua, com as respectivas variantes, tem um enorme valor que lhe é inerente, e é, portanto, digna de ser preservada e perpetuada, independentemente da sua situação política, demográfica e linguística; (b) as decisões referentes ao uso de uma língua, e aos objetivos desse uso, são um direito humano básico dos membros da comunidade que usam essa língua no presente, ou cujos antepassados a utilizaram no passado; (c) decisões quanto ao uso de uma língua devem ser tomadas numa atmosfera de tolerância e respeito mútuo pelos particularismos culturais - condição prévia não só para uma melhor compreensão mútua entre os povos, mas também para a aceitação da nossa comum condição humana. 
ou seja, "o estudo de como essas comunidades se relacionam com o meio ambiente físico". Podemos fazer a distinção entre (i) macrotoponímia, que se ocupa dos acidentes geográficos de grande porte (cadeia de montanhas, grandes rios, lagos etc); e (ii) microtoponímia, que está relacionada ao meio ambiente físico imediato dos membros destas comunidades (Couto, 2007, p. 250).

c) Etnozoologia: "é o estudo das relações entre humanos e animais em pequenas comunidades." Essa área do conhecimento preocupa-se com o modo como os indivíduos das comunidades tradicionais percebem, manejam e classificam as espécies animais de seu meio ambiente. Esse uso pode ser para alimentação, como fonte de proteínas; para manufaturas feitas de peles e ossos; para a cura de males e doenças (zooterapia); para o trabalho e, até mesmo, para o lazer (Couto, 2007, p. 234).

d) Etnomedicina: "é o estudo de como as pessoas das comunidades indígenas, tradicionais e rurais lidam com as doenças, as dores e os males em geral, tanto físicos quanto psíquicos”. A etnomedicina não está baseada somente na fitoterapia e na zooterapia, ou seja, no uso de produtos tirados de plantas e de animais, mas também nos processos de cura como benzeções, simpatias e outros (Couto, 2007, p. 243).

e) Etnobotânica: o conhecimento etnobotânico é o estudo das interações entre língua e meio ambiente, tendo como base os conhecimentos tradicionais sobre o uso das plantas. Tais investigações levam em consideração "por que determinada planta tem nome e por que outra não o tem; se o conhecimento sobre ela se transmite de geração para geração, e como se transmite; e o reflexo dessa transmissão ou não transmissão para as gerações seguintes e assim por diante" (Couto, 2007, p. 226).

Com o intuito de ilustrar como ocorre a inter-relação entre diversidade ecológica, cultural e linguística refletida no léxico de 
comunidades tradicionais, apresentamos uma investigação sobre os nomes de plantas, tendo como base o conhecimento etnobotânico de comunidades quilombolas do nordeste goiano. ${ }^{9}$

Os membros das comunidades Kalunga citaram 245 espécies de plantas para diversos usos, sendo:

Quadro 1. Número de espécies citadas de acordo com o uso

\begin{tabular}{|l|l|l|}
\hline $\begin{array}{c}\text { Número de } \\
\text { espécies citadas }\end{array}$ & \multicolumn{1}{|c|}{ Uso de cada espécie } & $\%$ \\
\hline 193 & Espécies para fins medicinais & $78,8 \%$ \\
\hline 131 & Espécies exclusivas de uso medicinal & $53,5 \%$ \\
\hline 52 & Espécies alimentícias & $21,2 \%$ \\
\hline 15 & Espécies exclusivas de uso alimentar & $6,1 \%$ \\
\hline 37 & Espécies para construção & $15,1 \%$ \\
\hline 16 & Espécies exclusivas para construção & $6,5 \%$ \\
\hline 16 & Espécies para outros fins & $6,5 \%$ \\
\hline 01 & Espécie exclusiva para outro fim & $0,4 \%$. \\
\hline
\end{tabular}

Observa-se que o maior número de espécies citadas é para fins medicinais (incluindo as plantas exclusivas de uso medicinal), depois para uso alimentar e, em seguida, para construção. É perceptível que além da alimentação e da moradia, necessidades básicas para a sobrevivência, há uma grande preocupação por parte dos membros dessas comunidades com a saúde, com a cura das dores e dos males em geral por meio do uso da flora local.

9. Os dados adiante apresentados dizem respeito à pesquisa de mestrado do Departamento de Engenharia Florestal da Universidade de Brasília, realizada pela Engenheira Florestal Natália do Prado Massarotto. Aqui serão respeitados todos os direitos reservados ao seu trabalho. Ressalta-se que as fontes citadas com base em seus estudos possuem um caráter científico e serão utilizadas sob uma abordagem metodológica de base bibliográfica. Os dados foram coletados entre setembro de 2007 e janeiro de 2009, por meio de entrevistas feitas em quatro comunidades quilombolas Kalunga (Emas, Limoeiro, Ribeirão de Bois e Engenho II) e quatro populações urbanas (Teresina de Goiás, Cavalcante, São Jorge e Alto Paraíso). No entanto, para o estudo aqui proposto, serão utilizados apenas os dados referentes às comunidades tradicionais rurais, já que o foco está na etnoecologia linguística. 
Quando os moradores das comunidades quilombolas Kalunga precisam de algum atendimento médico, estes têm que se deslocar até cidades mais próximas (Teresina de Goiás, Monte Alegre ou Cavalcante), muitas vezes caminhando. $\mathrm{O}$ isolamento das comunidades intensifica o uso de plantas medicinais nativas do Cerrado (Massarotto, 2009, p. 6).

Conforme Carlson (2001), a maioria das populações rurais não tem acesso aos modernos produtos farmacêuticos para as suas necessidades de saúde. A medicina tradicional botânica, assim como a zoológica, provê uma forma barata ou gratuita de tratamento para essas comunidades. Isso deve-se ao fato de que a medicina moderna não se encontra acessível para grande parte destas comunidades devido aos altos custos, vida útil dos medicamentos e ausência de pessoas treinadas para receitá-los e administrá-los.

Massarotto (2009) ressalta que, nos últimos anos, vem crescendo o aproveitamento, de forma sistematizada, do conhecimento popular da flora do cerrado com a produção de medicamentos na forma de pomadas, xaropes, soluções tópicas cicatrizantes e fungicidas, soluções e comprimidos para tratamento de vermes, entre outros, graças ao trabalho de lideranças e associações comunitárias com o apoio das universidades. Tais fatores demonstram como estão intrinsecamente relacionados os conhecimentos destas pequenas comunidades com a sua forma de lidar e interagir com o seu meio ambiente.

Outro importante aspecto presente na pesquisa de Massarotto (2009) diz respeito ao predomínio de espécies nativas do cerrado citadas pelos membros das comunidades Kalunga estudadas:

Quadro 2. Tipos de espécies mais citadas pelas comunidades Kalunga

\begin{tabular}{|l|l|l|l|l|}
\hline \multicolumn{1}{|c|}{ Comunidade } & $\begin{array}{c}\text { Espécies } \\
\text { nativas } \\
\text { do cerrado (\%) }\end{array}$ & $\begin{array}{c}\text { Espécies } \\
\text { cultivadas } \\
(\%)\end{array}$ & $\begin{array}{c}\text { Espécies } \\
\text { introduzidas } \\
(\%)\end{array}$ & $\begin{array}{c}\text { Espécies } \\
\text { compradas no } \\
\text { comércio (\%) }\end{array}$ \\
\hline Emas & 70,1 & 17,2 & 10,3 & 2,4 \\
\hline Limoeiro & 77,3 & 16,5 & 4,1 & 2,1 \\
\hline Ribeirão de bois & 65,9 & 25,4 & 6,3 & 2,4 \\
\hline Engenho II & 57,7 & 32,7 & 6,2 & 3,4 \\
\hline
\end{tabular}


Os dados contidos no quadro 2 nos dão indicações sobre a experiência que essas comunidades têm com o seu meio ambiente circundante, e ainda revelam que a manutenção da inter-relação desses indivíduos com as plantas nativas estão inteiramente relacionadas com a manutenção do cerrado. A perda da biodiversidade pode não somente provocar a diminuição das espécies nativas, como também ocasionar o desaparecimento do conhecimento etnobotânico de tais comunidades.

Veremos no quadro seguinte a importância que as 'coisas' do meio ambiente têm para a comunidade de indivíduos humanos que com elas convivem, via denominação (e uso). Couto (2007) nos lembra que os membros de qualquer comunidade nomeiam tudo, e só, aquilo que de alguma maneira apresenta algum tipo de interesse para eles.

O autor ainda nos diz que só recebem um nome aquelas plantas que de alguma forma representa algum interesse (positivo ou negativo) para a comunidade local ou, pelo menos, chamam atenção pelo formato, pelo odor, pelo tamanho ou por outra característica. Só recebem um nome as plantas com as quais os membros da comunidade local interagem de alguma forma.

Quadro 3. Nome popular das plantas e seu principal uso

\begin{tabular}{|l|l|}
\hline Nome popular da espécie & Principal uso \\
\hline Carrapicho & dor de barriga, gripe, inflamação \\
\hline alfavaca & Gripe \\
\hline assa-peixe & Gripe \\
\hline Grapiá & febre, gripe \\
\hline pacari & corrimento, ferida, fígado \\
\hline amburana mansa & pneumonia e dor \\
\hline erva-cidreira & calmante, pressão alta \\
\hline mangaba & dor de barriga \\
\hline mentraz & dor de estômago, inflamação \\
\hline Pixuri & Dor \\
\hline mastruz & ferida \\
\hline capim-santo & Gripe \\
\hline manjericão & Gripe \\
\hline Quina & gripe, resguardo \\
\hline chapada & Gripe \\
\hline sucupira branca & dor de garganta \\
\hline Algodão & gripe e ferida \\
\hline Arruda & dor de cabeça \\
\hline capim-de-cacho & Gripe \\
\hline & \\
\hline
\end{tabular}


Embora o número de termos ${ }^{10}$ apresentados no quadro 3 seja pequeno ${ }^{11}$, é possível analisarmos alguns aspectos referentes à designação dos nomes das plantas citadas pelos membros das comunidades Kalunga. No que diz respeito aos 19 nomes, percebemos que:

a) Quatro denominações aparecem formadas por palavras compostas: erva-cidreira, capim-santo, capim-de-cacho e assa-peixe. A primeira pelo esquema $\mathrm{N}+\mathrm{N}$ (eira); em seguida, $\mathrm{N}+\mathrm{A}$ (nome+adjetivo); a outra $\mathrm{N}$ de $\mathrm{N}$, e, por último $\mathrm{V}+\mathrm{N}$ (verbo+nome);

b) Além da forma composta por justaposição $\mathrm{N}+\mathrm{A}$, nos termos anteriormente citados, aparecem mais duas ocorrências do esquema $\mathrm{N}+\mathrm{A}$ : amburana mansa e sucupira branca.

c) Não foi registrada nenhuma ocorrência de palavras com referência ao diminutivo $(\mathrm{N}+$ inho) nem o oposto semântico aumentativo.

d) Há a maior presença de lexemas simples indecomponíveis: carrapicho, alfavaca, grapiá, pacari, mangaba, mentraz, pixuri, mastruz, manjericão, quina, chapada, algodão e arruda.

Com base no esquema proposto Boretzky (1987), por meio do qual o autor defende a ideia de que é possível detectar tendências gerais na denominação de plantas, é possível reagrupar alguns nomes contidos no quadro 3 .

10. Não procuramos neste trabalho analisar como os processos de percepção, identificação e nominação das plantas foram e estão organizados pelos membros desta comunidade, com vistas à compreensão da formação linguística dos nomes ou termos atribuídos às plantas. O objetivo proposto é descrever as inter-relações existentes entre língua, cultura e meio ambiente com base no conhecimento etnobotânico de comunidades tradicionais e seu reflexo no léxico.

11. O trabalho realizado por Massarotto (2009) apresenta um número bem maior de espécies citadas pelos membros dessas comunidades, destacando outros usos e função, conforme quadro 3. Foram apresentados aqui apenas algumas palavras de maior ocorrência no vocabulário etnobotânico dos membros das comunidades pesquisadas. 
a) o sentido da visão: capim de cacho e sucupira branca

b) traços do formato: capim de cacho

c) lugares: chapada

Couto (2007) acrescenta outros processos de denominação que ampliam ainda mais a possibilidade de análise desses termos, como a indicação de processos metonímicos e/ou metafóricos, a exemplo de amburana mansa, capim-de-cacho e capim-santo.

Apoiando-nos na abordagem de Sapir (1969, p. 45) sobre 'língua e ambiente', podemos verificar, com base nos termos apresentados, como "o léxico da língua é que mais nitidamente reflete o ambiente físico e social dos falantes". O autor ressalta ainda que o "léxico completo de uma língua pode se considerar, na verdade, como o complexo inventário de todas as ideias, interesses e ocupações que açambarcam a atenção da comunidade".

Desse modo, observamos que a mera existência ou presença destas plantas no meio ambiente circundante da comunidade não seria a garantia da nomeação ou presença do conhecimento etnobotânico partilhado pelos membros da comunidade. A exposição dos especialistas apresentados nos revelam que é preciso que a 'coisa' (neste caso 'as plantas') seja conhecida ou represente algum interesse para os indivíduos do grupo.

\section{Considerações finais}

Por meio da revisão bibliográfica, ou seja, com base em alguns estudos que inter-relacionam a diversidade ecológica, a diversidade cultural e a diversidade linguística, procuramos mostrar como a língua é um sistema constituído por uma complexidade natural na qual se integram os fenômenos sociais e os fenômenos ecológicos, não podendo a língua existir isolada de seus ambientes ou ecossistemas.

Vimos também que o atual modelo político-econômico tem colocado em risco a preservação dos ecossistemas e, além disso, 
provocado imensuráveis danos às culturas locais, como a perda de conhecimentos tradicionais e o desaparecimento de línguas minoritárias. Tais ocorrências nos levam a repensar nossas atitudes e a buscar ferramentas pautadas na colaboração das diversas áreas do conhecimento (acadêmico e tradicional) com vistas a uma melhor compreensão e, consequentemente, respeito às diversas manifestações culturais e linguísticas espalhadas nos diferentes ambientes de nosso planeta.

Outro aspecto abordado foi o processo de nomeação das plantas pelos indivíduos da comunidade Kalunga, evidenciando muito mais que a simples identificação das espécies presentes no meio em que vivem, mas a presença de um vocabulário estritamente relacionado ao seu conhecimento etnobotânico, específico da identidade da comunidade. Dito de outro modo, as espécies da flora nomeadas pelos membros desta comunidade tradicional só recebem um nome de acordo com o grau de importância que têm para essas pessoas: uso para construção, alimentação, cura de doenças etc. Assim, o nome surge quando os membros da comunidade precisam falar da 'coisa', isto é, no contexto da interação comunicativa, na convivência destes indivíduos ao longo do tempo, e no ambiente em que vivem.

Nesse sentido, o conhecimento etnobotânico ou, de forma mais ampla, o conhecimento etnoecológico, revela-se como um importante instrumento de estudo das interações entre língua, cultura e meio ambiente. A forma como os membros das pequenas comunidades interagem, trocam experiências, repassam seus conhecimentos, preservam suas tradições e lidam com o meio ambiente são de grande importância para a preservação da diversidade biológica, diversidade cultural e diversidade linguística.

Recebido: 10/11/2012

Aceito: 15/12/2012

gilberto@equipetrilhar.com.br 


\section{Referências bibliográficas}

BORETZKY, N. Lexikalische Natürlichkeit: Benennungsmotive in Pflanzenname. In: BORETZKY, N.; W.; ENNINGER; T. STOLZ (orgs.). Beiträge zum 3. Essener Kolloquium über Sprachwandel und seine bestmmende Faktoren, p. 53-76. Bochum: Brockmeyer, 1987.

CARLSON, T. J. Language, ethnobotanical knowledge, and tropical public health, p. 489-502. In: MAFFI, Luisa (org.), On biocultural diversity: Linking language, knowledge, and the environment, 2001.

COUTO, H. H. do. Ecolinguística: estudos das relações entre língua e meio ambiente. Brasília: Tessaurus, 2007.

MAFFI, L. (org). On biocultural diversity: Linking language, knowledge, and the environment. Washington: Smithsoniam Institution Press, 2001.

Linguistic, Cultural and Biological Diversity. Annu. Rev. Anthropol. 29, 2005, p. 599-617. Disponível em:<http://www.terralingua.org/wp/content/ uploads/downloads/2011/01/ARA_review.pdf > . Acesso em 05/08/2012.

MASSAROTTO, N. P. Diversidade e uso de plantas medicinais por comunidades quilombolas kalungas e urbanas no nordeste do Estado de Goiás - GO, Brasil. Dissertação de Mestrado em Ciências Florestais (inédita). Brasília: Universidade de Brasília, 2009.

MÜHLHÄUSLER, P. Ecolinguistics, linguistic diversity, ecological diversity, p. 133-144. In: L. MAFFI (org.). Washington: Smithsoniam Institution Press, 2001.

Ecolinguistics in the University. Perspective of Linguistic Diversity. Adelaide: Sangensha Publishers, 2010.

RODRIGUES, A. D. Biodiversidade e diversidade etnolingüística na Amazônia. In: SIMÕES, M. do S. (org.). Cultura e biodiversidade entre o rio e a floresta, $1^{\mathrm{a}}$ ed. Belém: Universidade Federal do Pará, 2001, v. 1, p. 269-278. Disponível em: < http://www.amazoe.org.br/textoreferencia/ biodiversidade_e_diversidade_etnolinguistica.pdf>. Acesso em: 05/08/2012.

SAPIR, E. A linguística como ciência: ensaios. Rio de Janeiro: Livraria Acadêmica, 1969.

SMITH, E. On the coevolution of cultural, linguistic, and biological diversity, p. 95-117. In: L.MAFFI (org.). Washington: Smithsoniam Institution Press, 2001. 